\title{
AD/ART dan Bisnis Plan sebagai Penguatan Kelembagaan Bank Sampah Induk Pelangi Siak Sri Indrapura
}

\author{
Jeni Wardi*1, Alexsander Yandra ${ }^{2}$, Junaidi ${ }^{3}$, Latifa Siswati ${ }^{4}$, Ambar Tri Ratnaningsih 5 \\ 1,2,3,4,5 Universitas Lancang Kuning \\ *e-mail: jeniwardi@unilak.ac.id¹, alexsy@unilak.ac.id², junaidi@unilak.ac.id ${ }^{3}$, latifasiswati@unilak.ac.id ${ }^{4}$, \\ ambar_trn@yahoo.com ${ }^{5}$
}

\begin{abstract}
Recent developments related to Bank Sampah Induk Pelangi (BSIP) after receiving assistance from the waste bank program from Chevron and UNILAK, there has been an increase in activities and more effective governance. In this program, the Bank Sampah Induk Pelangi has received equipment/tools assistance to capacity building. Capacity Building that has been provided in the first year, namely training on composting fertilizer for the management of the Bank Sampah Induk Pelangi and Waste Bank Unit, training on making paving blocks from plastic waste, Occupational Health and Safety Training, training on product packaging and online marketing, and training on the use and maintenance of machines. machine operators, both press and chopper. But in its journey, the Bank Sampah Induk Pelangi still has problems in terms of unclear organizational structures, job descriptions, unprofessionalism, and the sustainability of the Waste Bank's business and business. human capacity building and institutional strengthening of the rainbow parent waste bank, namely training on making basic budgets/household budgets and waste bank business plans. This training uses the method of presenting material on the preparation of the basic budget/household budget and the waste bank business plan as well as the practical and simulation method of making the basic budget/household budget and the waste bank business plan. The result of this training is that the management of the Bank Sampah Induk Pelangi has been able to draft the articles of association and bylaws and business plans, so that the management of the waste bank already understands the benefits of the articles of association and by-laws and business plans. Besides that, the management of the Rainbow Main Waste Bank also understands matters relating to the importance of a business plan for the sustainability of the waste bank in the future.
\end{abstract}

Keywords: Training, Articles of Association, Bylaws, Business Plan, Waste Bank.

\begin{abstract}
Abstrak
Perkembangan terakhir terkait Bank Sampah Induk Pelangi (BSIP) setelah mendapatkan bantuan program bank sampah dari Chevron dan UNILAK terlihat peningkatan aktifitas dan tata kelola yang lebih efektif. Yang mana dalam program ini, Bank Sampah Induk Pelangi telah mendapat bantuan peralatan/tools hingga capacity building. Capacity Building yang telah diberikan pada tahun pertama yaitu Pelatihan pembuatan pupuk kompos pada pengurus Bank Sampah Induk Pelangi dan Bank Sampah Unit, Pelatihan pembuatan paving block dari sampah plastic, Pelatihan Kesehatan Keselamatan Kerja, Pelatihan pengemasan produk dan marketing online, dan Pelatihan Penggunaan dan Perwatan mesin para operator mesin baik press maupun pencacah. Tapi dalam perjalananya Bank Sampah Induk Pelangi tersebut masih mempunyai masalah dalam hal ketidakjelasan struktur organisasi, gambaran pekerjaan (job description), ketidakprofesionalitasan, dan keberlanjutan usaha dan bisnis Bank Sampah Oleh sebab itu Kami Tim Bank Sampah Chevron-Unilak memberikan solusi dalam mengatasi permasalahan ini melalui peningkatan kapasitas manusia dan penguatan kelembagaan bank sampah induk pelangi, yaitu pelatihan pembuatan anggaran dasar/anggaran rumah tangga dan rencana bisnis (business plan) bank sampah. Pelatihan ini menggunakan Metode peyampakan materi tentang pembuatan anggaran dasar/anggaran rumah tangga dan rencana bisnis (business plan) bank sampah serta metode praktik dan simulasi pembuatan anggaran dasar/anggaran rumah tangga dan rencana bisnis (business plan) bank sampah. Hasil dari pelatihan ini adalah pengurus Bank Sampah Induk Pelangi sudah bisa membuat drafanggaran dasar dan anggaran rumah tangga dan rencana bisnis, sehingga pengurus bank sampah sudah paham dengan manfaat anggaran dasar dan anggaran rumah tangga dan rencana bisnis. Disamping itu pengurus bank sampah induk pelangi juga memahami hal-hal yang berkaitan dengan pentingnya rencana bisnis bagi keberlanjutan bank sampah kedepannya.
\end{abstract}

Kata kunci: Pelatihan, Anggaran Dasar, Anggaran Rumah Tangga, Bisnis Plan, Bank Sampah. 


\section{PENDAHULUAN}

Pengelolaan sampah dengan mandiri diharapkan dapat menjadi salah satu kunci untuk mengatasi permasalahan sampah di suatu wilayah. Sampah akhir-akhir ini masih menjadi topik permasalahan secara nasional. Hal ini dikarenakan kesadaran masyarakat sangat minim terhadap permasalahan sampah. Titik awal pengelolaan sampah yang baik dan tepat adalah berawal dari rumah tangga yaitu dengan memilah-milah sampah, karena sampah rumah tangga setiap hari dihasilkan secara berkelanjutan. Begitu juga dengan sampah pasar, yang juga membutuhkan kesadaran para pedagang dalam mengatasi dan pengelolaannya. Harus dibangun atau dibuat sistem pengelolaan persampahan terpadu yang dikelola oleh masyarakat dan pemerintah. (Putri et al., 2018).

Bank sampah Induk Pelangi yang diketuai oleh Bapak Fauzan Azima dan beralamat di Jl. Panglima Udan No. 1, RT 07 RW 02, Kel. Kampung Rempak, Kab. Siak berdiri sejak tahun 2013 menjadi Bank Sampah Induk di Kabupaten Siak berdasarkan keputusan Bupati Siak Nomor 193.HK/KPTS/2018 yang Mewadahi 12 Unit Bank Sampah yang di tingkat kecamatan di Kabupaten Siak. Berdasarkan keputusan Bupati Siak Nomor 193/HK/KPTS/2018 Bank Sampah Induk Pelangi (BSIP) adalah bank sampah induk dibawah lindungan dan binaaan Dinas Lingkungan Hidup (DLH) Kabupaten Siak. BSIP merupakan mitra Unilak dalam program bank sampah dengan chevron. Bank sampah induk pelangi memiliki peran yang sangat penting dalam menjaga lingkungan dari bahaya sampah (zero waste), bahkan sejak adanya BSIP ini Kabupaten Siak 5 kali berturut-turut mendapatkan pengahargaan Adipura Kencana.

Bank Sampah ini sudah disupport dengan berbagai jenis mesin dan peralatan administrasi baru yang diperoleh dari program Bank Sampah PT. CPI dan Universitas Lancang Kuning. Saat ini Bank Sampah Pelangi telah memiliki 700 nasabah dengan rincian 500 nasabah aktif serta sudah mempunyai produk pupuk kompos dengan merk Darling (Daur Ulang Lingkungan). Perkembangan terakhir terkait Bank Sampah Induk Pelangi (BSIP) setelah mendapatkan bantuan program bank sampah dari Chevron dan UNILAK terlihat peningkatan aktifitas dan tata kelola yang lebih efektif. Yang mana dalam program ini, Bank Sampah Induk Pelangi telah mendapat bantuan peralatan/tools hingga capacity building. Capacity Building yang telah diberikan pada tahun pertama yaitu Pelatihan pembuatan pupuk kompos pada pengurus Bank Sampah Induk Pelangi dan Bank Sampah Unit, Pelatihan pembuatan paving block dari sampah plastic, Pelatihan Kesehatan Keselamatan Kerja, Pelatihan pengemasan produk dan marketing online, dan Pelatihan Penggunaan dan Perwatan mesin para operator mesin baik press maupun pencacah.

Masalah bank sampah pada umumnya dari sisi manajemen organisasi yaitu bank sampah belum menyusun struktur organisasi mulai dari pengambilan sampah sampai kepada penjualan sampah serta administrasi yang akan mencatat dan menimbang sampah yang telah dipilah oleh masyarakat, masalah berikutnya adalah operasional bank sampah, dimana belum disusun lay out operasional yang efektif pada proses mulai dari pengambilan sampah dari masyarakat lalu dipisahkan dan dipilah-pilah sampai kepada penjualan sampah serta administrasi yang akan menimbang dan mencatat harga sampah tersebut (Wardi, et al., 2020).

Begitu juga halnya dengan Bank Sampah Induk Pelangi tersebut masih mempunyai masalah dalam hal ketidakjelasan struktur organisasi, gambaran pekerjaan (job description), ketidakprofesionalitasan, dan keberlanjutan usaha dan bisnis Bank Sampah. Karena organisasi Bank Sampah ini berbentuk sosial sehingga sangat besar pengaruhnya terhadap motivasi kerja anggota Bank Sampah. Pembagian peran antar anggota di Bank Sampah juga masih didasarkan pada teori pertukaran yakni menekankan kepada sosiologi perilaku agar memusatkan perhatian pada hubungan antara pengaruh perilaku seorang aktor terhadap lingkungan dan dampak lingkungan terhadap aktor (Susanti, Winarno, \& Saryanti, 2020). Penguatan kelembagaan menjadi isu yang sangat penting karena terkait dengan komunikasi antar anggota sehingga mampu memenuhi kinerja kontekstual (contextual performance) di samping kinerja tekstual (textual performance) yang hanya berbicara tentang pengetahuan tentang label dari pekerjaan 
tersebut saja (Aguinis, 2013). Nantinya kelembagaan ini diharapkan dapat memberikan akuntabilitas public kepada seluruh stakeholder, dan memastikan asset organisasi aman dan termanfaatkan dengan benar (Putri et al., 2018).

Oleh sebab itu solusi dalam mengatasi permasalahan ini adalah melalui peningkatan kapasitas manusia dan penguatan kelembagaan bank sampah induk pelangi, yaitu pelatihan pembuatan anggaran dasar/anggaran rumah tangga dan rencana bisnis (bussinis plane) bank sampah yang ditaja oleh Tim Bank Sampah Chevron-Unilak. Dengan mengetahui seberapa banyak profit yang akan dihasilkan, maka tak jarang banyak pemilik yang membutuhkan banyak waktu dalam menentukan harga penjualan. Perencanaan yang matang adalah sebuah kunci sukses berdirinya sebuah bisnis. Dimana bisnis tersebut nantinya akan tetap berkembang jika direncanakan dengan baik (Wardi, et al., 2021).

Berdasarkan analisis situasi dan latar belakang tersebut di atas, maka perumusan permasalahan Bank Sampah Induk Pelangi adalah Bagaimana solusi dalam mengatasi permasalahan ketidakjelasan struktur organisasi, gambaran pekerjaan (job description), ketidakprofesionalitasan, dan keberlanjutan usaha dan bisnis Bank Sampah.

Adapun solusi dalam mengatasi permasalahan ini adalah melalui peningkatan kapasitas manusia dan penguatan kelembagaan bank sampah induk pelangi melalui pelatihan yang ditaja oleh Tim Bank Sampah Chevron-Unilak dengan rincian adalah Tim akan memberikan konsep dan teori tentang pembuatan anggaran dasar/ anggaran rumah tangga dan rencana bisnis (bussinis plan) bank sampah dan Tim akan melakukan pendampingan dan praktek simulasi pembuatan anggaran dasar/anggaran rumah tangga dan rencana bisnis (bussinis plan) bank sampah.

\section{METODE}

Adapun metode penelitian dalam riset ini yaitu Pelatihan diselenggarakan dengan ceramah, tanya jawab, dan praktik.

1. Ceramah dan tanya jawab

Metode ini digunakan untuk menyampaikan materi tentang pembuatan anggaran dasar/anggaran rumah tangga dan rencana bisnis (bussinis plan) bank sampah.

2. Praktik

Pada sesi ini peserta akan di dampingi dalam praktek simulasi terkait pembuatan anggaran dasar/anggaran rumah tangga dan rencana bisnis (bussinis plan) bank sampah.

Kegiatan ini melibatkan beberapa unsur masyarakat, diantara adalah RT/RW, Lurah, Pengurus dan personil Bank Sampah Induk Pelangi, Pengurus dan personil Bank Sampah Unit, dan Mahasiswa. Evaluasi kegiatan pengabdian ini dilakukan dengan cara mengukur keberhasilan kegiatan dengan menetapkan tolak ukur yaitu Meningkatnya pengetahuan dan keterampilan pengelola bank sampah pembuatan anggaran dasar/anggaran rumah tangga dan rencana bisnis (bussinis plan) bank sampah, indikatornya dapat dilihat dari hasil output yang dihasilkan oleh peserta yaitu berupa draf AD-ART dan Bussinis Plan.

Tim pengabdian dalam pengabdian ini adalah Dosen dan dibantu Mahasiswa Program Studi Akuntansi Fakultas Ekonomi Universitas Lancang Kuning, yang telah memiliki pengalaman dalam kegiatan pengabdian pada masyarakat, termasuk penyuluhan, sosialisasi, praktek pelatihan dan lain-lainnya. Tim memiliki bidang keahlian dengan disiplin yang sama tapi spesifikasi yang berbeda, sehingga mampu saling menunjang dalam kegiatan Pengabdian Kepada Masyarakat (PKM) ini. 


\section{HASIL DAN PEMBAHASAN}

Kegiatan pelatihan pembuatan anggaran dasar/anggaran rumah tangga dan rencana bisnis (bussinis plan) telah dilaksanakan pada hari selasa tanggal 04 Mei 2021 dimulai pada pukul 09.00 WIB dan berakhir pada pukul 12.00 WIB bertempat di Bank Sampah Induk Pelangi Siak Sri Indrapura, dihadiri oleh 13 orang pengurus, baik ketua, sekretaris, bendahara, maupun anggota lainnya.

Pelaksanaan Pelatihan pembuatan anggran dasar/anggaran rumah tangga dan rencana bisnis berlangsung dengan baik dan lancar, mendapatkan respon yang baik dari peserta, hal ini terlihat dari peserta sangat konsentrasi mendengaran penjelasan teori dan konsep pembuatan anggaran dasar/anggaran rumah tangga dan rencana bisnis dan juga mereka sangat antusias bertanya kepada narasumber.

Hasil dari pelatihan ini pengurus Bank Sampah Induk Pelangi sudah bisa membuat draf anggaran dasar dan anggaran rumah tangga dan rencana bisnis, sehingga pengurus bank sampah sudah paham dengan manfaat anggaran dasar dan anggaran rumah tangga dan rencana bisnis.
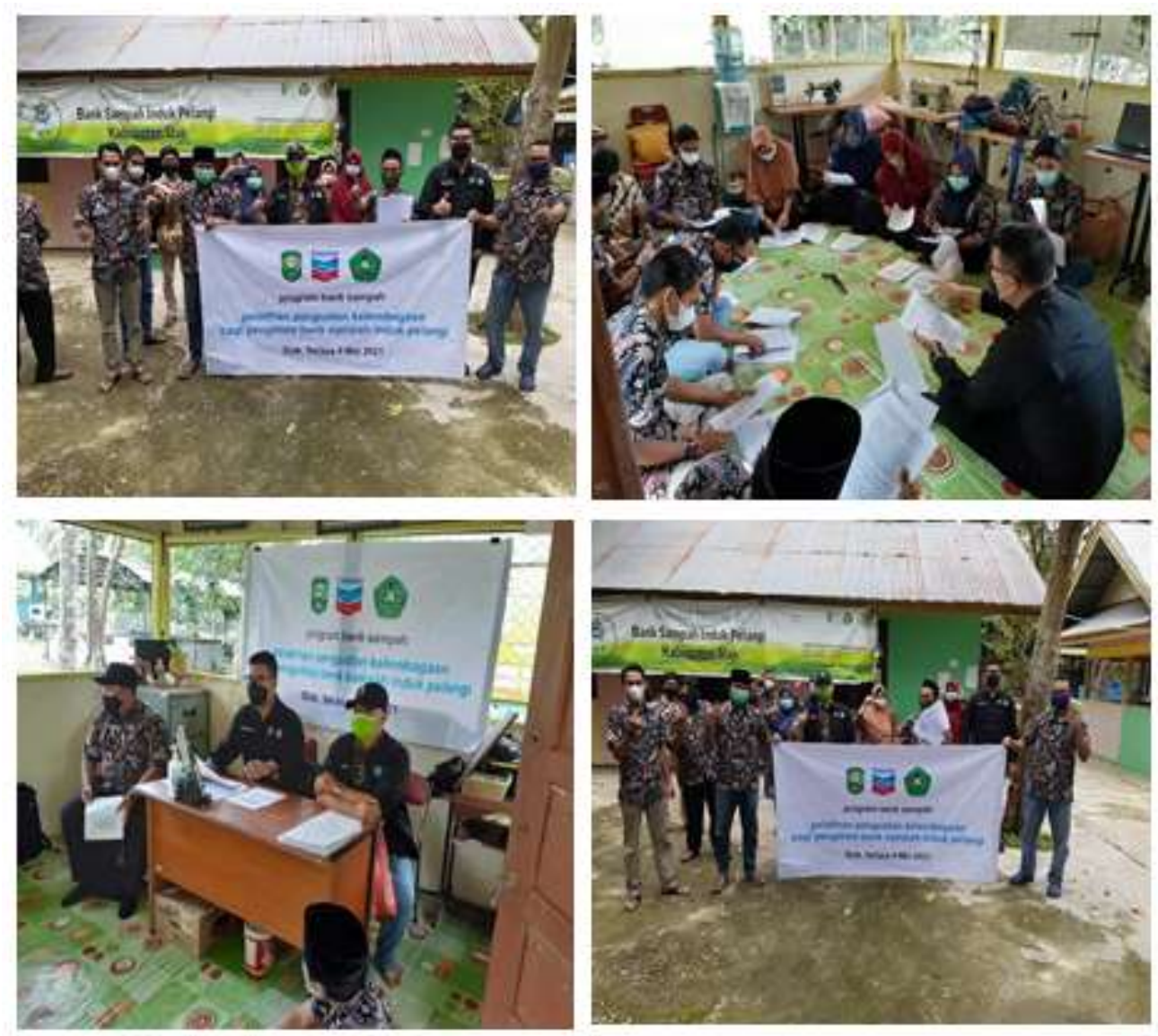

Gambar 1. Pelatihan Pembuatan Anggaran Dasar/Anggaran Rumah Tangga Dan Rencana Bisnis di Bank Sampah Induk Pelangi

Pengurus Bank Sampah Induk Pelangi setelah mengikuti pelatihan dan pendampingan pembuatan anggaran dasar/anggaran maka pengurus jadi sangat paham mengenai AD/ART adalah bentuk perikatan dalam berorganisasi yang menjadi pedoman bagi semua pihak yang terkait dalam organisasi, baik dalam pengelolaan tata kehidupan organisasi maupun usaha. Secara rinci, AD/ART dijelaskan berikut ini: Anggaran Dasar (AD), yaitu keseluruhan aturan umum yang meliputi pengaturan secara langsung kehidupan organisasi dan hubungan organisasi dengan anggotanya agar tercipta tertib organisasi. AD memuat ketentuan-ketentuan pokok yang 
merupakan dasar bagi tata kehidupan organisasi. Ketentuan dalam AD digunakan sebagai acuan dalam membuat peraturan-peraturan organisasi secara lebih khusus. Dengan kata lain, AD sebagai pondasi yang mengikat dan mengatur anggota untuk bekerja sama dalam melakukan kegiatan organisasi. ART, yaitu himpunan peraturan yang mengatur urusan rumah tangga seharihari, yang merupakan penjabaran lebih lanjut dari AD.

Disamping itu pengurus bank sampah induk pelangi juga memahami hal-hal yang berkaitan dengan pentingnya rencana bisnis bagi keberlanjutan bank sampah kedepannya. Karena banyak orang yang merintis bisnis tanpa persiapan yang matang. Padahal, persiapan dibutuhkan demi kemajuan bisnis jangka panjang. Salah satu persiapan penting yang harus dilakukan adalah membuat perencanaan usaha atau dikenal juga dengan istilah business plan. Perencanaan usaha merupakan dokumen yang menggambarkan tujuan berdirinya suatu bisnis dan mekanisme operasionalnya secara keseluruhan. Di dalam dokumen perencanaan usaha harus ada penjelasan rinci tentang strategi pemasaran, kondisi keuangan perusahaan, pendapatan dan pengeluaran bisnis, serta data penting lain yang menunjukkan tujuan bisnisnya harus tercapai.

Pengurus bank sampah juga akhirnya memahami manfaat perencanaan usaha, baik untuk perorangan atau kelompok, yaitu:
a) Mengetahui model bisnis yang dijalani
b) Target market jelas
c) Mencari sumber dana
d) Rencana bisnis jadi lebih fokus dan terarah
e) Untuk memprediksi masa depan
f) Menaikkan level bisnis dengan baik

\section{KESIMPULAN}

Penguatan kelembagaan Bank sampah induk pelangi melalui pelatihan pembuatan anggaran dasar/anggaran rumah tangga dan rencana bisnis dengan metode pelaksanaan penilaian awal (initial assessment) permasalahan dan identifikasi permasalahan dilakukan melalui wawancara, serta praktik pembuatan anggaran dasar /anggaran rumah tangga mampu meningkatkan pengetahuan, pemahaman pengurus bank sampah induk pelangi mengenai $\mathrm{AD} / \mathrm{ART}$ adalah bentuk perikatan dalam berorganisasi yang menjadi pedoman bagi semua pihak yang terkait dalam organisasi, baik dalam pengelolaan tata kehidupan organisasi maupun usaha. Secara rinci, AD/ART dijelaskan berikut ini: Anggaran Dasar (AD), yaitu keseluruhan aturan umum yang meliputi pengaturan secara langsung kehidupan organisasi dan hubungan organisasi dengan anggotanya agar tercipta tertib organisasi. AD memuat ketentuan-ketentuan pokok yang merupakan dasar bagi tata kehidupan organisasi. Ketentuan dalam AD digunakan sebagai acuan dalam membuat peraturan-peraturan organisasi secara lebih khusus. Dengan kata lain, AD sebagai pondasi yang mengikat dan mengatur anggota untuk bekerja sama dalam melakukan kegiatan organisasi. ART, yaitu himpunan peraturan yang mengatur urusan rumah tangga seharihari, yang merupakan penjabaran lebih lanjut dari AD.

Selanjutnya peserta pelatihan juga memahami hal-hal yang berkaitan dengan pentingnya rencana bisnis bagi keberlanjutan bank sampah kedepannya. Karena banyak orang yang merintis bisnis tanpa persiapan yang matang. Padahal, persiapan dibutuhkan demi kemajuan bisnis jangka panjang. Salah satu persiapan penting yang harus dilakukan adalah membuat perencanaan usaha atau dikenal juga dengan istilah business plan. Perencanaan usaha merupakan dokumen yang menggambarkan tujuan berdirinya suatu bisnis dan mekanisme operasionalnya secara keseluruhan. Di dalam dokumen perencanaan usaha harus ada penjelasan rinci tentang strategi pemasaran, kondisi keuangan perusahaan, pendapatan dan pengeluaran bisnis, serta data penting lain yang menunjukkan tujuan bisnisnya harus tercapai. 


\section{DAFTAR PUSTAKA}

Aguinis, H. (2013). Performance Management: International Edition. New York: Pearson Education.

Putri, L. D., \& Harsini, S. R. (2018). Potential of Regulation of Slum Area in The Village Meranti Pandak Pekanbaru City. International Journal of Engineering \& Technology, 7(2), 466-469.

Putri, L. D., nasution, sri roserdevi, \& harsini, harsini. (2018). Efektivitas Lembaga Keswadayaan Masyarakat (LKM) Dalam Pengentasan Kawasan Kumuh di Kecamatan Rumbai Kota Pekanbaru. Jurnal Niara, 11(1), 96-100. https://doi.org/10.31849/nia.v11i1.1784

Sudjatmiko, S. (2013). Mengapa Departemen SDM Dibenci? Gramedia Pustaka Utama.

Susanti, N. I., Winarno, W., \& Saryanti, E. (2020). Pelatihan Aplikasi Administrasi Manajemen Sampah pada Bank Sampah RT. 04 RW. 07 Desa LangenhajoGrogol-Sukoharjo. WASANA NYATA, 4(2), 95-107.

Wardi, J., Putri, G. E., \& Liviawati. (2021). Bimtek Harga Pokok Penjualan Produk Bank Sampah Berkah Abadi Limbungan Rumbai Pekanbaru. 0761, 3-6. DOI.https://doi.org/10.35446/diklatreview.v5i2.622

Wardi, J., Putri, G. E., \& Liviawati. (2021). Pelatihan Manajemen Bank Sampah Berkah Abadi Kelurahan Limbungan Kecamatan Rumbai Pesisir Kota Pekanbaru. 0761. DOI.https://doi.org/10.35446/diklatreview.v4i3.524 